H, Fujita T, et al. Complete agenesis of the dorsal pancreas. $J$ Hepatobiliary Pancreat Surg. 1999;6:94-7.

2. Johansson KA, Grapin-Botton A. Development and diseases of the pancreas. Clin Genet. 2002;62:14-23.

3. Bretagne JF, Darnault P, Raoul JL, Gardon Y, Gosselin M, Cousin $P$, et al. Calcifying pancreatitis of a congenital short pancreas: a case report with successful endoscopic papillotomy. Am J Gastroenterol. 1987;82:1314-7.

4. Lumb G, Beautyman W. Hypoplasia of the exocrine tissue of the pancreas. J Pathol Bacteriol. 1952; 64:679-86.

5. Gilinsky NH, Del Favero G, Cotton PB, Lees WR. Congenital short pancreas: a report of two cases. Gut. 1985;26:304-10.

6. Morita M, Otsubo C, Kozu T, Shibata I, Toki F, Oi I, et al. Aplasia of the body and tail of the pancreas-a report of two cases (article in Japanese). Nihon Shokakibyo Gakkai Zasshi. 1980;77:102-6.

\section{Multiple gastrointestinal and extragastrointestinal stromal tumors in a male infant - an extreme rarity}

\section{Introduction}

GISTs are defined as submucosal mesenchymal neoplasms of the gastrointestinal tract, having spindle cell, epitheloid or pleomorphic morphology and characteristic positive immunostaining for CD117 antigen. ${ }^{1}$ Until recently, they were regarded as smooth muscle neoplasms and categorized as leiomyosarcomas, leiomyomas or leiomyoblastomas. ${ }^{2}$ In 1983 , Mazur and Clark coined the term stromal tumors to describe the group of mesenchymal neoplasms that lacked ultrastructural and immunophenotypic features of smooth muscle differentiation. ${ }^{3}$

GISTs in pediatric age group are rare and constitute about $1 \%$ to $2 \%$ of all GIST cases and they mostly occur in females with a female to male ratio of $9: 1{ }^{4}$ These are located most commonly in stomach (50-60\% of lesions) and less commonly in small intestines (20-30\%), large intestine (10\%) and esophagus (5\%). ${ }^{1}$ There have been reports of GISTs occurring in extra gastrointestinal locations, primarily the mesentery, omentum and retroperitoneum, but these are rare. They are thought to originate from the interstitial cells of Cajal, the pacemaker cells of gastrointestinal tract like both of them express the receptor tyrosine kinase (KIT) which stain with
CD117 antigen. ${ }^{2}$ Over expression of KIT due to activating mutations seems to be the trigger factor for neoplastic growth of GISTs. ${ }^{5,6}$

So, it can be emphasized that multiple pediatric gastrointestinal stromal tumors occurring simultaneously at gastrointestinal (terminal ileum) as well as extragastrointestinal (mesentery and omentum) locations in a male infant is a rarity.

\section{Case Report}

A six months old male child with normal birth history and uneventful neonatal period was brought to the Accident and Emergency department with complaints of pain abdomen, vomiting, distention abdomen and non passage of stools for 4 days. There was no history of bleeding per rectum / malena. On examination, the child was febrile, tachypnoeic, had tachycardia (pulse rate-120/min) and normal blood pressure. On abdominal examination, the abdomen was distended and there was a single hard lump of about $9 \times 6 \mathrm{~cm}$ present in the right iliac quadrant which was movable to some extent along two axes, perpendicular to each other. The child was investigated and an $\mathrm{X}$ ray abdomen showed multiple air fluid levels suggestive of intestinal obstruction (Figure 1). Ultrasonography revealed a soft tissue tumor in the right lower quadrant of the abdomen arising from the small intestine. CT scan of the abdomen was not done in view of urgency due to acute intestinal obstruction.

The child was taken up for surgery and on exploration, there was a extra-luminal hard tumor of size $8 \times 6 \times 5 \mathrm{~cm}$ on the anti-mesenteric border of the terminal ileum about $5 \mathrm{~cm}$ proximal to ileocaecal junction causing obstruction due to compression resulting in dilatation of whole of the small intestine proximal to the tumor (Figure 2). In addition, there were multiple small rounded hard tumors in mesentery $(n=2)$ and greater omentum $(\mathrm{n}=3)$ varying in diameter from $0.5 \mathrm{~cm}$ to $1.5 \mathrm{~cm}$. The liver and all other viscera appeared to be normal. About $7 \mathrm{~cm}$ segment of terminal ileum, bearing the tumor, along with its mesentery and a margin of $2 \mathrm{~cm}$ was resected and all the small tumors in omentum and mesentery were also excised (Figure 3 ) and end to end ileo-ileal anastomosis was done.

The patient died of septicemia on $4^{\text {th }}$ post operative day. On histopathological examination, grossly the tumor was oval, homogenous, grey white, firm and on anti-mesenteric surface of ileum. Microsections from all the tumors (the large one as well as all the small ones) showed features of gastrointestinal stromal tumors comprising of spindle cells as well as epitheloid 


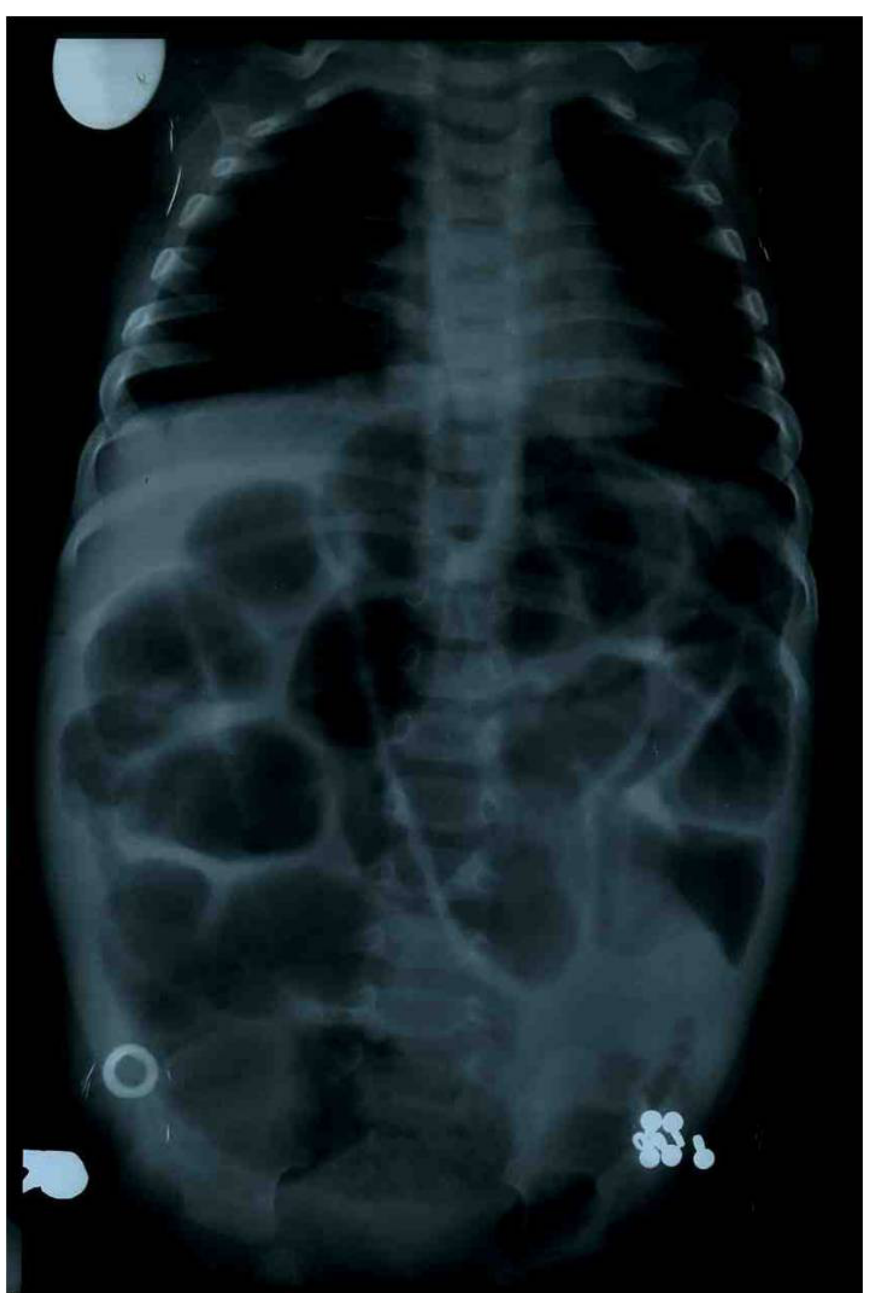

Figure 1: Plain X-ray abdomen showing multiple dilated bowel loops suggestive of intestinal obstruction.

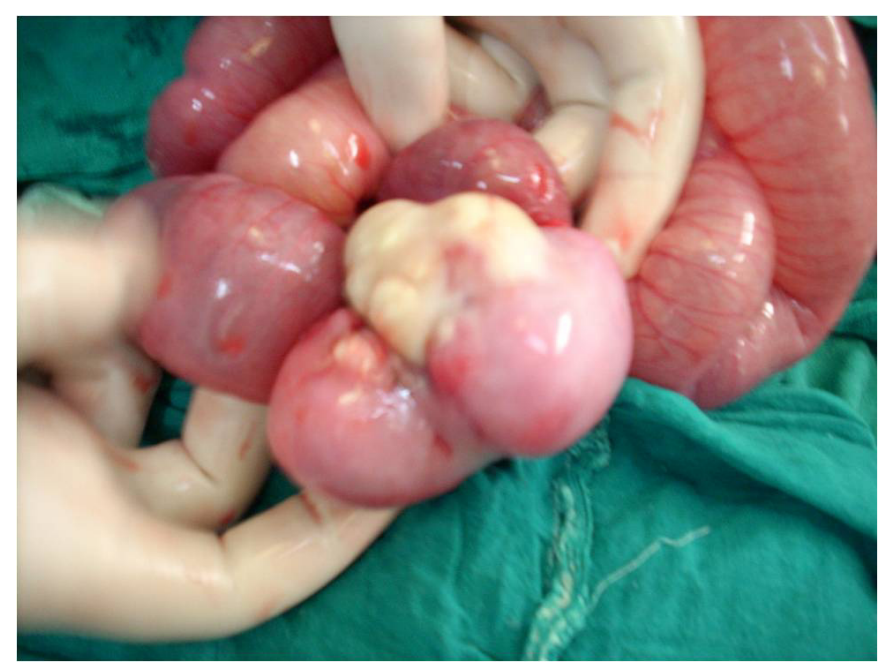

Figure 2: Operative photograph showing a hard oval tumor on the antimesenteric border of terminal ileum with dilated small intestine proximal to the tumor.

cells. There was mild pleomorphism and low mitotic activity. The tumors also showed infiltration by chronic inflammatory cells. Since the tumor was large ( $>5 \mathrm{~cm}$ ) and there were multiple tumors, it fell into high risk category inspite of low mitotic activity.

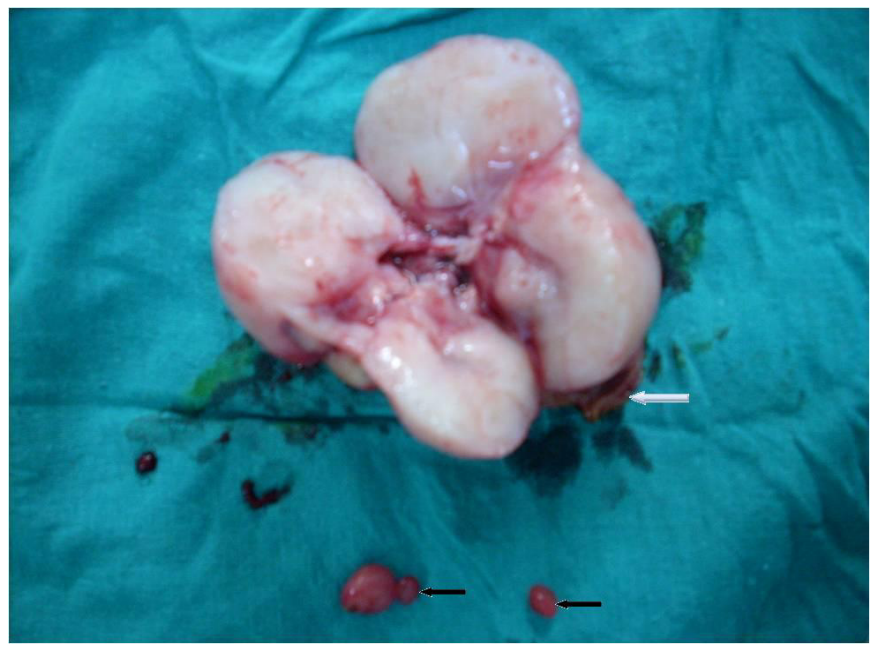

Figure 3: Cut section of the resected tumor with free margin of the ileum (marked with white arrow) along with smaller tumors resected from the omentum (marked with black arrows).

\section{Discussion}

Recently, Li et al suggested that GISTs in children have features distinct from adults : female predominance, predilection for gastric location and occurrence in the second decade of life. ${ }^{7}$ But since our patient was a 6 months old male infant having GISTs involving ileum, mesentery and omentum, none of these features were present in him.

Surgical resection is the mainstay of treatment for GISTs. Resection should be complete with tumor free margins and should always include mesentery of the involved segment with avoidance of tumor rupture and spillage into peritoneal cavity. GISTs rarely metastasize to lymph nodes. Therefore, lymphadenectomy is usually not needed.

Predictors of unfavorable clinical behavior in GISTs include tumor size $>5 \mathrm{~cm}$, mucosal invasion, a non gastric primary site and high mitotic activity. ${ }^{1,6}$ Therefore, the GISTs in our case had a high risk of aggressive behavior owing to large size (biggest tumor diameter $=8 \mathrm{~cm}$ ) and non gastric primary sites (ileum, omentum and mesentery) inspite of having low mitotic activity and non involvement of mucosa. But follow up was not possible since the patient died on $4^{\text {th }}$ post operative day. Tumor recurrence is seen in 40 to $80 \%$ of patients despite complete surgical resection of the primary tumors and typically involves the primary site followed by the liver and peritoneal surface. Treatment options for recurrent disease are limited and include systemic or intraperitoneal chemotherapy, surgery, arterial embolization and radiotherapy, but the response rates to these are extremely low $(<10 \%)$. Recently, owing to better understanding of this disease at molecular level, there has been emphasis on targeted therapies utilizing imatinib mesylate, a 
competitive inhibitor of KIT and platelet derived growth factor receptor á (PDGFR á)and the results have been encouraging in patients having unresectable or metastatic GISTs. ${ }^{8}$

\section{KAMAL NAIN RATTAN ${ }^{1}$ PRADEEP KAJAL ${ }^{1}$ VIVEK SINGH MALIK ${ }^{2}$ GARGI SONI ${ }^{3}$}

\author{
Correspondence: Dr. Pradeep Kajal, \\ Department of Pediatric Surgery ${ }^{1}$ and Anatomy ${ }^{2}$ \\ PGIMS Rohtak, Haryana and Department of Anatomy \\ MAMC, Agroha, Haryana, India-124001 \\ Email: drpradeepkajal@gmail.com
}

\section{References}

1. Fletcher CD, Berman JJ, Corless C, Gorstein F, Lasota J, Longley BJ, et al. Diagnosis of gastrointestinal stromal tumors: A consensus approach. Hum Pathol. 2002;33:459-65.

2. Chan JK. Mesenchymal tumors of the gastrointestinal tract: a paradise for acronyms (STUMP, GIST, GANT, and now GIPACT), implication of c-kit in genesis, and yet another of the many emerging roles of the interstitial cell of Cajal in the pathogenesis of gastrointestinal diseases? Adv Anat Pathol. 1999;6:19-40.

3. Mazur MT, Clark HB. Gastric stromal tumors. Reappraisal of histogenesis. Am J Surg Pathol. 1983;7:507-19.

4. Perez-Atayde AR, Shamberger RC, Kozakewich HW. Neuroectodermal differentiation of the gastrointestinal tumors in the Carney triad. An ultrastructural and immunohistochemical study. Am J Surg Pathol. 1993;17:706-14.

5. Rubin BP, Singer S, Tsao C, Duensing A, Lux ML, Ruiz R, et al. KIT activation is a ubiquitous feature of gastrointestinal stromal tumors. Cancer Res. 2001;61:8118-21.

6. Berman J, O'Leary TJ. Gastrointestinal stromal tumor workshop. Hum Pathol. 2001;32:578-82.

7. Li P, Wei J, West AB, Perle M, Greco MA, Yang GC. Epithelioid gastrointestinal stromal tumor of the stomach with liver metastases in a 12-year-old girl: aspiration cytology and molecular study. Pediatr Dev Pathol. 2002;5:386-94.

8. Demetri GD, von Mehren M, Blanke CD, Van den Abbeele $\mathrm{AD}$, Eisenberg B, Roberts PJ, et al. Efficacy and safety of imatinib mesylate in advanced gastrointestinal stromal tumors. $N$ Engl J Med. 2002;347:472-80.

\section{Spleen preserving distal pancreatectomy for a large papillary}

\section{cystic and solid tumor of the pancreas}

\section{Introduction}

Most pancreatic tumors are malignant and have a bad prognosis. However, papillary cystic and solid tumour of the pancreas (PCSTP) is an unusual low-grade malignancy that rarely metastasizes. ${ }^{1}$ Surgical resection is generally curative and the prognosis is excellent. It mostly affects young females with a mean age of 25 years. ${ }^{2}$ It has also been referred to as a solid-cystic epithelial tumour, solid-pseudopapillary tumour or papillary-cystic tumour. ${ }^{3}$ It makes up $0.2-2.7 \%$ of all pancreatic cancers. ${ }^{4}$ Since the original description by Frantz in 1959, the incidence of PCSTP has been increasing, ${ }^{5}$ although it may be that it is increasingly being diagnosed. Very few cases of PCSTP have been reported from India.

\section{Case report}

A 29-year-old female presented with chronic epigastric and left hypochondriac discomfort since 1 year. It was associated with postprandial fullness and occasional vomiting. On examination she was overweight and there was epigastric tenderness, vague mass was palpable in the left hypochondrium which moved with respiration. All haematological and biochemical parameters were within normal limits. Abdominal ultrasonography demonstrated partially cystic mass of $18 \times 12 \mathrm{~cm}$ in distal pancreas with a possibility of a neoplasm. Contrast enhanced computed tomography (CT) scan confirmed $18 \mathrm{~cm}$ mass in the tail of pancreas without any metastases.

The patient underwent staging laparoscopy which showed large mass arising from the tail of the pancreas without any metastases. An en-block spleen preserving distal pancreatectomy, including the pancreatic mass, was performed (Figure 1). The patient made an uneventful recovery.

On gross examination the pancreatic tumour was oval, 18 $\mathrm{cm}$ in diameter, and was surrounded by a fibrous pseudocapsule. Its cut surface showed solid and cystic spaces. On microscopy, the solid portion of the tumour revealed sheets of uniform polygonal cells as well as non-cohesive papillae arranged around fine fibrovascular cores. The cyst wall was composed of dense acellular fibrous tissue within which the tumour cells were arranged as cords and trabeculae set within a mucinous background. No invasion of the tumour into 